\title{
Identification of bio-climatic determinants and potential risk areas for Kyasanur forest disease in Southern India using MaxEnt modelling approach
}

\author{
Malay Pramanik, Poonam Singh and Ramesh C. Dhiman * (1)
}

\begin{abstract}
Background: Kyasanur forest disease (KFD), known as monkey fever, was for the first time reported in 1957 from the Shivamogga district of Karnataka. But since 2011, it has been spreading to the neighbouring state of Kerala, Goa, Maharashtra, and Tamil Nadu. The disease is transmitted to humans, monkeys and by the infected bite of ticks Haemaphysalis spinigera. It is known that deforestation and ecological changes are the main reasons for KFD emergence, but the bio-climatic understanding and emerging pathways remain unknown.

Methods: The present study aims to understand the bio-climatic determinants of distribution of tick vector of KFD in southern India using the Maximum Entropy (MaxEnt) model. The analysis was done using 34 locations of Haemaphysalis spinigera occurrence and nineteen bio-climatic variables from WorldClim. Climatic variables contribution was assessed using the Jackknife test and mean AUC 0.859, indicating the model performs with very high accuracy.

Results: Most influential variables affecting the spatial distribution of Haemaphysalis spinigera were the average temperature of the warmest quarter (bio10, contributed 32.5\%), average diurnal temperature range (bio2, contributed 21\%), precipitation of wettest period (bio13, contributed 17.6\%), and annual precipitation (bio12, contributed 11.1\%). The highest probability of Haemaphysalis spinigera presence was found when the mean warmest quarter temperature ranged between 25.4 and $30^{\circ} \mathrm{C}$. The risk of availability of the tick increased noticeably when the mean diurnal temperature ranged between 8 and $10^{\circ} \mathrm{C}$. The tick also preferred habitat having an annual mean temperature (bio1) between 23 and $26.2{ }^{\circ} \mathrm{C}$, mean temperature of the driest quarter (bio9) between 20 and $28{ }^{\circ} \mathrm{C}$, and mean temperature of the wettest quarter (bio8) between 22.5 and $25^{\circ} \mathrm{C}$.

Conclusions: The results have established the relationship between bioclimatic variables and KFD tick distribution and mapped the potential areas for KFD in adjacent areas wherein surveillance for the disease is warranted for early preparedness before the occurrence of outbreaks etc. The modelling approach helps link bio-climatic variables with the present and predicted distribution of Haemaphysalis spinigera tick.
\end{abstract}

Keywords: Bio-climatic envelope model, Kyasanur forest disease, Haemaphysalis spinigera tick, Monkey disease, Tickborne disease, Hemorrhagic fever

*Correspondence: r.c.dhiman@gmail.com

Environmental Epidemiology Division, ICMR-National Institute of Malaria Research, Sector 8, Dwarka, Delhi 110077, India

\section{Introduction}

Kyasanur forest disease (KFD) is a zoonotic tick-borne viral disease, first reported from the forested area of Shivamogga district, Karnataka, in 1957 [1]. The disease is 
caused by the KFD virus belonging to the family Flaviviridae and genus Flavivirus, measuring about 40-60 nm in diameter [2-4]. The KFD virus genome consists of 10,774 nucleotides of single-stranded, positive-sense RNA encoding a single polyprotein [3]. The virus genome is very similar to that of Alkhurma Hemorrhagic Fever Virus (>92\% homologous), which is primarily found in Saudi Arabia [4]. These two species both belong to the family Flaviviridae and diverged over 700 years ago and have thus remained geographically separated [4].

The virus was found to be highly infectious, as evidenced by several infections in laboratory and field staff $[5,6]$, which resulted in work suspension until a proper Biosafety Level-3 laboratory was established at ICMRNational Institute of Virology in 2004. In nature, the virus is found in ticks, monkeys, shrews, bats and small mammals [7, 8]. KFD is transmitted to animals and humans by the infected tick bites, mainly Haemaphysalis spinigera [9-12]. The incubation period of the KFD virus is 3-8 days [13]. The symptoms of KFD include a high fever with frontal headaches, severe muscle pain, vomiting, chills, and other gastrointestinal symptoms [13]. Bleeding problems can occur 3-4 days after the onset of the initial symptom. Patients may have unusually low blood pressure as well as low red and white blood cell, and platelet counts [13].

A variety of animals are thought to be reservoir hosts for the disease, including rats, porcupines squirrels, shrews, and mice. Monkeys are the main amplifying host of KFD, they come out to human dwellings and their death signals the outbreak in human beings [7, 14]. Monkeys (red-faced Macaca radiata and black-faced Presbytis entellus) are the reservoirs of KFD, but they also die due to KFD [8]. The KFD virus is highly contagious in the bonnet macaques and surili Presbytis entellus. They become extremely virulent and infect ticks. Haemaphysalis spinigera, a forest tick, serves as the disease's vector [11]. The bite of tick nymphs causes infection in humans. Because the human domestic environment does not support ticks, man is a terminal host, and there is no humanto-human transmission $[9,12]$.

It frequently occurs in semi-evergreen, evergreen, deciduous and moist forests in southern India only [14] and has also been related to developmental activities resulting in deforestation [15] and ecological changes [8]. Population with occupational exposure to outdoor or rural settings (i.e., herders, hunters, farmers, and forest workers) in the villages are potentially at risk of the disease if they contact infected Haemaphysalis spinigera ticks $[3,8]$. The disease prevails in the dry months from November to May, when the nymphs' density is maximum in the forest due to favourable moisture in the soil of forest areas [16-18]. The average temperature in the dry months has increased substantially over the years and this has led to water crisis in the region [15]. The disease is localized in several districts, namely Chikmagalur, Shivamogga, Udupi, Dakshina Kannada, and Uttar Kannada of the Karnataka state, India [6, 12]. Since the first reporting of the disease from the Shivamogga district in 1957, several sporadic cases and outbreaks have been reported every year in the same region $[4,7,19,20]$. But, in the past few years (i.e., 2013 onwards), the geographical range of the disease has extended to the districts in Kerala, Goa, Maharashtra, and Tamil Nadu (Fig. 1).

The reason for the spread of KFD to nearby areas is not known. It is assumed that ecology and bioclimatic variables are responding to such spatial distribution. Previous studies by Ajesh et al. [14], Banerjee and Bhatt [5] showed that the disease extends, ranges and changes happen due to the influence of ecological destructions and by the eventual effects of resulting climate change $[5,14]$. But, the climatic factors are not fully understood. Therefore, to prove this hypothesis, we have used Ecological Niche to establish the climatic predictors of tick distribution in the study region based on presence/absence data [24, 25]. The model has been devised by Phillips et al. [24] and Yang et al. [25], based on the MaxEnt entropy algorithm [24] can evaluate the predictors role as well as predict the distribution of a species, even with the very limited presence data [26, 29]. It is a well-established algorithm to identify the potential suitability of different epidemic diseases, vectors, and fauna \& flora species [26-30]. The risk assessments and prediction of hosts and vectors using the MaxEnt algorithm have been investigated in other vector-borne diseases like malaria, leishmaniasis, Rift Valley fever virus, dengue, West Nile virus, and japanese encephalitis [31-35]. The results of the species distribution model can help improve tick monitoring, surveillance and guide for implementing control programmes [31, 36, 37].

It was thought prudent to understand the bioclimatic factors responsible for present distribution as well as the potential distribution of Haemaphysalis spinigera in India. Therefore, the present study used the ecological niche modelling (MaxEnt) approach to determine the risk areas of KFD and climatic sensitivity of Haemaphysalis spinigera for southern India based on field survey and existing occurrence data. In addition, our modelling results explained the link between model-based favourable climatic conditions and the possibility of monkey death and KFD tick expansion in the endemic and potential areas in other parts of India. The tool is the only efficient strategy for controlling and preventing the disease 


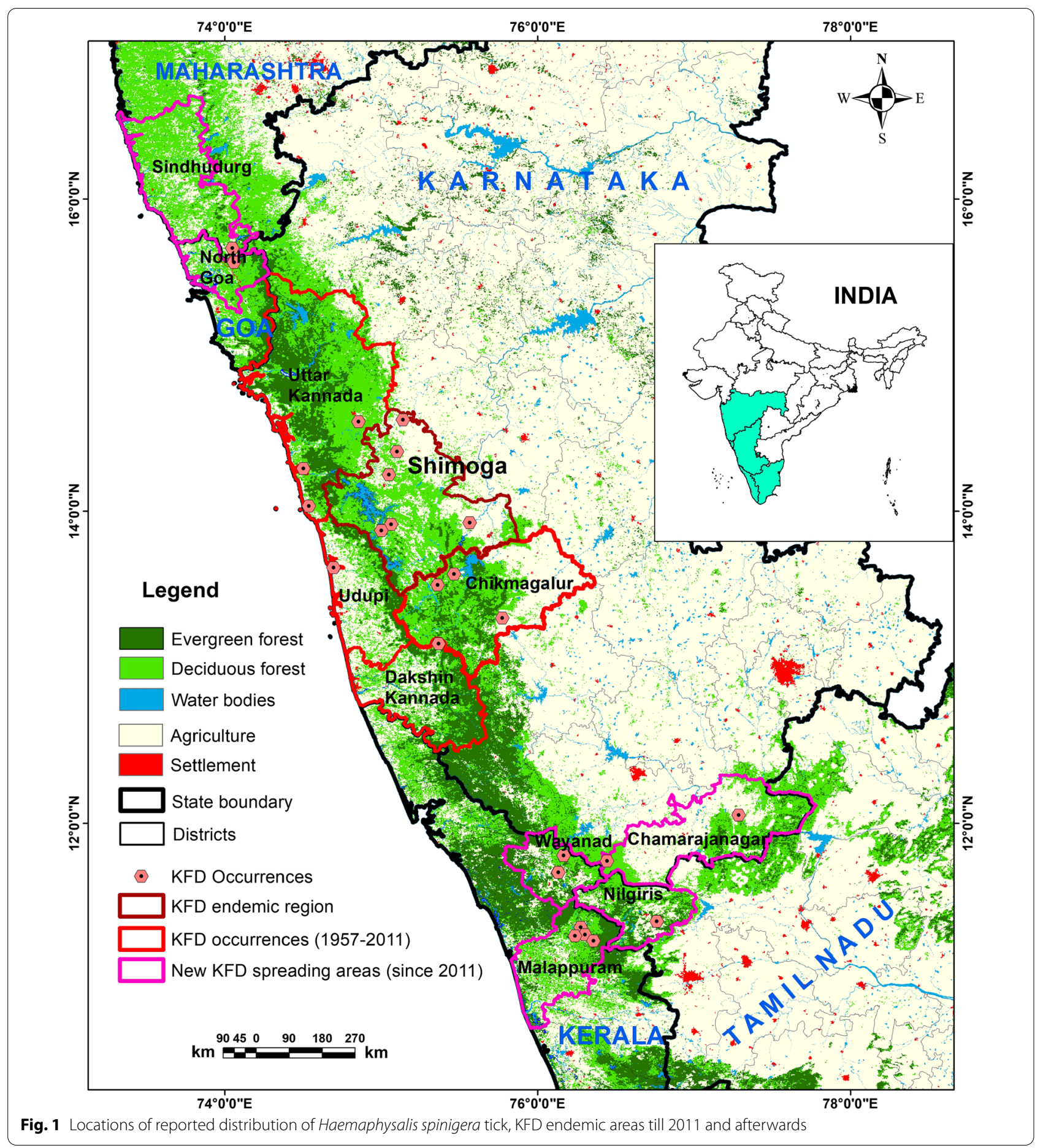

to find out the biological and climatic risk of Haemaphysalis spinigera and KFD.

\section{Materials and methods}

Haemaphysalis spinigera tick occurrence data

Data on reported availability of Haemaphysalis spinigera were collated by systematic and comprehensive literature retrieval from the google scholar, Cochrane library, PubMed and the Web of science database, by 
using the keywords Kyasanur forest disease, Haemaphysalis spinigera occurrence, monkey death by KFD virus, KFD in India, human cases of KFD (Additional file 1). The literature dealing with the availability of Haemaphysalis spinigera, the occurrence of KFD cases or monkey death from 1957 onwards were considered to ascertain the coordinates. Location of confirmed cases (human cases and monkey death) were converted into point features (exact latitude and longitude, $1 \mathrm{~km} \times 1 \mathrm{~km}$ ) or polygon features (i.e., localities, villages, districts) georeferenced using Google Earth and Arc-GIS for the rectification of latitude and longitude [38]. When the name of the locality or village could not be identified at the administrative level, the coordinates were overlaid in a geographic information system (GIS) and assigned to the appropriate polygon feature [38]. All the locations of the occurrence of Haemaphysalis spinigera tick were transformed into WGS 84 datum using Arc-GIS software. Since the present study was conducted by the resolution of 30 arc-second (approximately $1 \mathrm{~km} \times 1 \mathrm{~km}$ resolution), localities within one pixel were selected as one occurrence point. Altogether, 34 locations with confirmed human cases, monkey deaths or availability of Haemaphysalis spinigera ticks were georeferenced from all the reported areas of Karnataka, Maharashtra, Kerala, Goa, and Tamil Nadu (Fig. 1) (Additional file 1: Table S1). These occurrence locations were used for the MaxEnt model input, as the model predicts very accurately with very limited presence and absence datasets $[26,29,36]$.

\section{Bio-climatic variables}

Bio-climatic variables are biologically more significant to identifying plants and animals' physio-ecological resistance than simple temperature and rainfall $[39,40]$. Therefore, these variables are commonly used in bioclimate envelope modelling [31, 41]. The study used 19 bio-climatic variables as potential predictors of Haemaphysalis spinigera distribution (as shown in Additional file 1: Table S2). Raster-based bio-climatic variables were collected from the WorldClim Version2 (http://www. worldclim.com/version2). The spatial resolution of these bio-climatic layers is $\sim 1 \mathrm{~km}$ (30 arc seconds) and show extremity and seasonality of temperature, annual trends of precipitation and temperature parameters.

Of 19 bio-climatic variables, five extremely correlated variables, having a negligible effect on the model, were removed to reduce the masking effect and produce a model with better predictability [42]. The test was run by Pearson's correlation coefficient ( $r$ ) using ENM Tool (version 1.3), and a cross-correlation ' $r$ ' value of more than 0.80 was taken as a cut of threshold [25, 42] (Additional file 1: Table S3). Finally, the remaining 14 bio-climatic variables with a higher permutation significance and percent contribution were used for modelling. Based on the MaxEnt produced response curves, the relationship between bioclimatic variables and habitat suitability for Haemaphysalis spinigera occurrence were evaluated.

\section{Predictive modelling}

The ArcGIS 10.3 and ENVI 5.1 softwares were used to generate raster-based spatial layers of the bio-climatic variables. The maximum entropy (MaxEnt) modelling is a machine learning algorithm [24] that calculates the probability distribution for a vector or species location based on different environmental restraints. The model executes well even with fewer sampling points than other machine learning methods [43]. Using presence-only vector/species location points to predict the potential distribution based on MaxEnt theory [24]. The basic principle of this algorithm is to ensure that approximation meets any limitations on the unknown points, meaning that the calculated probability of unknown distribution represents less number of constraints with a set of extra choices [44, 45]. However, in this study, we used 34 locations' data about the presence of Haemaphysalis spinigera and generated pseudo-absences. The maximum entropy algorithm randomly selected about 10,000 background points. Data on the presence of ticks were divided into $75 \%$ random samples to calibrate the model, and the $25 \%$ random samples were utilized to assess the model performance. We used the subsampling method to create a stable model because it has advantages over bootstrap and cross-validation $[46,47]$, and 50 replicates were chosen to run the model.

The model also suggests settings to assess the complexity of the model by altering regularization multipliers and feature classes. Sixteen different combinations of the feature classes were created to identify the appropriate feature by retaining the linear function in each feature, then used for model performance. In order to balance the fit of the model and avoid overfitting, regularization multipliers were used [48]. The selected default value for model calibration is 1.0. In total, 123 models combinations were created for choosing the best fit model in different settings. Other values of the model were set as default to get better results.

\section{Threshold identification}

For model results indicating the probability of presence (suitability of a species), the logistic value ranging from 0 (unsuitable) to 1 (max. probability of presence) was used [24]. By applying 'max SSS' (maximum test sensitivity with specificity) logistic threshold value, 
binary unsuitable/maximum suitable map has been prepared. Specificity (Sp) and Sensitivity (Se), which are independent, implies the likelihood of a model that adequately forecasts a species absence and presence in any location and measures the commission and omission errors. Sp and Se are distincts and not influenced by predominant across models [49]. In the ROC curve, the "max SSS" identifies a point in which the tangent slope is 1 that demonstrates 1 -specificity and sensitivity for maximizing TSS value. The value can be utilized as an efficient threshold value when the only occurrence or target species presence data are available and used extensively [50-52]. This binary raster was used to show the potential distribution of the Haemaphysalis spinigera ticks using SDM toolbox 2.0. A bias file has corrected the selection of backgrounds for latitudinal changes resulting from the geographical coordinate systems [53].

\section{Model assessment and validation}

To estimate the goodness of fit of the model, the Area Under the receiver operating characteristics Curve (AUC) was used, and the highest value was indicated as the best performer. The AUC is a threshold-independent technique of a model assessment to discriminate outcomes of presence/absence [54]. AUC values vary from least value 0 to the highest value 1 . The 0.5 value signifies that the model findings were less than random, while the 1.0 value indicates complete discrimination $[54,55]$. In the Jackknife test, the contribution of the bio-climatic factors was also measured. The detailed methodological flow diagram in this work is shown in Fig. 2.

\section{Results \\ Model performance}

The logistic results for the presence of tick suitability and the distribution of Kyasanur forest disease were found highly significant. The AUC results for the training sample are 0.898 , and for the test, the sample is 0.859 (Fig. 3). This suggests that the bio-climatic variables set, used for the prediction model, and interpreted the predicted potential suitability very well with very high accuracy. The optimum threshold value, which provides equal weight to specificity and sensitivity, was selected to classify suitable areas of Haemaphysalis spinigera.

\section{Identified bio-climatic variables for distribution of Haemaphysalis spinigera}

Of 14 bio-climatic variables used for modelling, more influential variables affecting the spatial distribution

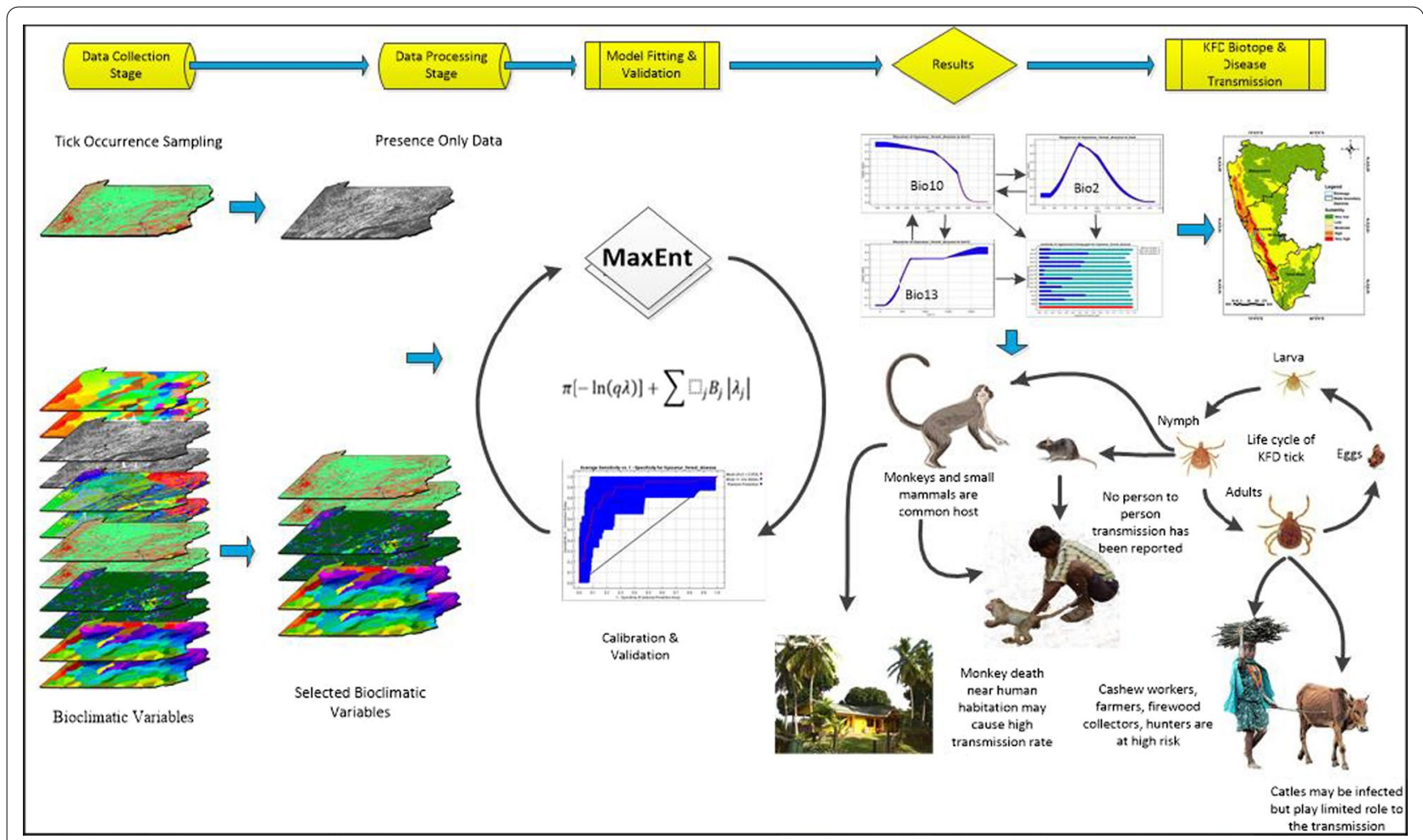

Fig. 2 Methodological flow diagram showing the link between suitable climatic conditions and disease transmission of Kyasanur forest disease 


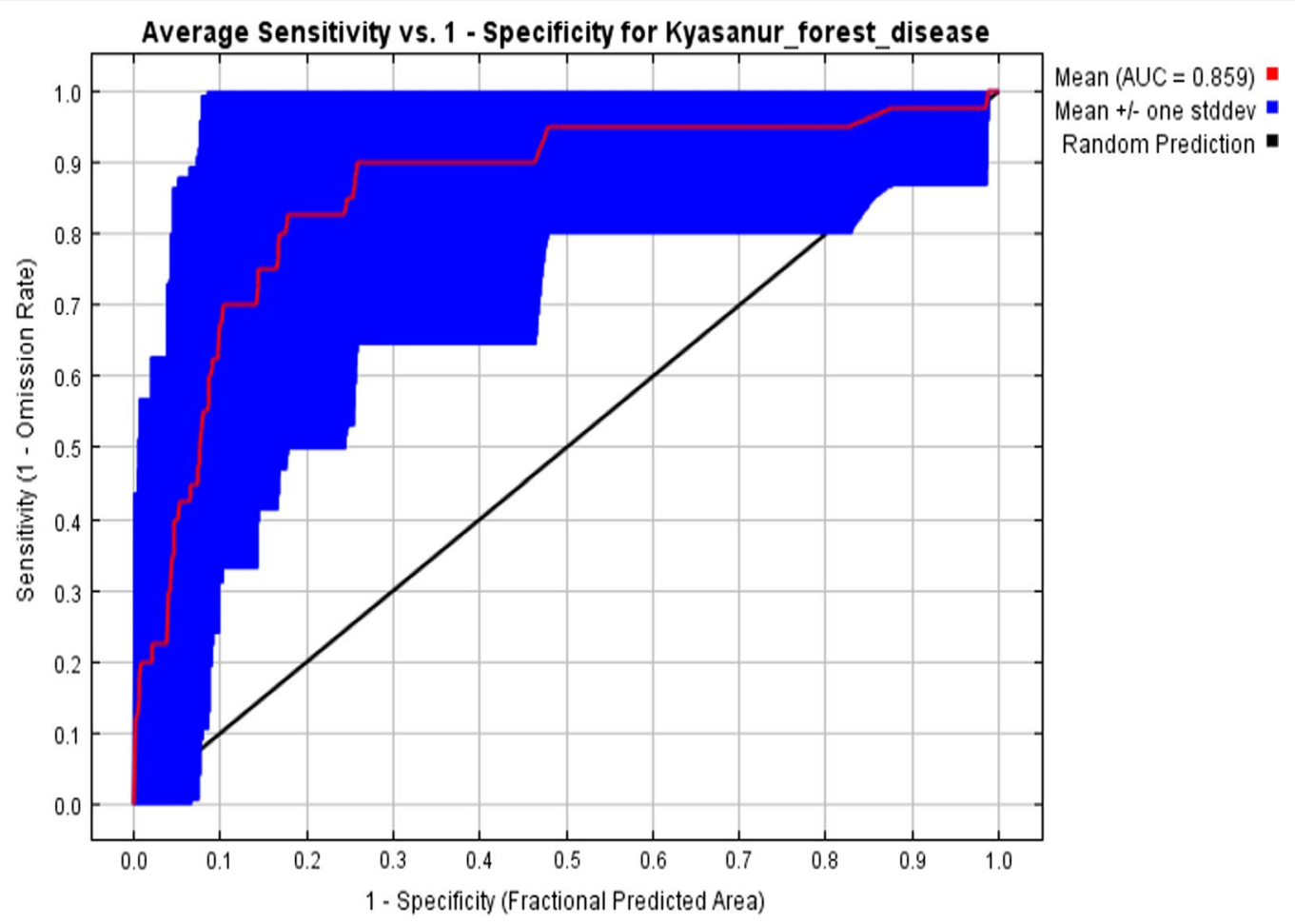

Fig. 3 The ROC curve for Haemaphysalis spinigera tick showing different AUC values

of Haemaphysalis spinigera were the average temperature of the warmest quarter (bio10, contributed 32.5\%), average diurnal temperature range (bio2, contributed $21 \%$ ), precipitation of wettest period (bio13, contributed $17.6 \%$ ), and annual precipitation (bio12, contributed $11.1 \%)$. The cumulative contribution of these variables was $82.2 \%$. The variable having high permutation importance was the average temperature of the warmest quarter $(40.1 \%)$. The remaining 12 variables, i.e., annual mean temperature (Bio1), average temperature of the driest quarter (bio9), average temperature of the coldest quarter (bio11), rainfall of the warmest quarter (bio18), mean temperature of the wettest quarter (bio8), precipitation of wettest quarter (bio16), rainfall of driest quarter (bio17), precipitation of driest period (bio14), and precipitation seasonality (bio15) contributed $17.8 \%$ altogether to the suitability model (Table 1). Therefore, the average temperature of the warmest quarter and mean diurnal temperature change are very significant variables contributing to the risk

Table 1 Selected set of bio-climatic variables after PCA results and their contribution to the KFD suitability

\begin{tabular}{llll}
\hline Id of bioclimatic variable & Selected bio-climatic variable & Contribution (\%) & $\begin{array}{c}\text { Optimum } \\
\text { bio-climatic } \\
\text { conditions }\end{array}$ \\
\hline Bio1 & Annual mean temperature & 0.1 & $23-26.2^{\circ} \mathrm{C}$ \\
Bio2 & Mean diurnal temperature range & 21 & $8-10^{\circ} \mathrm{C}$ \\
Bio8 & Mean temperature of wettest quarter & 2.4 & $22.5-25^{\circ} \mathrm{C}$ \\
Bio9 & Mean temperature of driest quarter & 0.5 & $20-2 ~^{\circ} \mathrm{C}$ \\
Bio10 & Mean temperature of warmest quarter & 32.5 & $25.4-30^{\circ} \mathrm{C}$ \\
Bio11 & Mean temperature of coldest quarter & 3.9 & $16.5^{\circ}-24 \mathrm{C}$ \\
Bio12 & Annual precipitation & 11.1 & $>1400 \mathrm{~mm}$ \\
Bio13 & Precipitation of wettest period & 17.6 & $500-650 \mathrm{~mm}$ \\
\hline
\end{tabular}




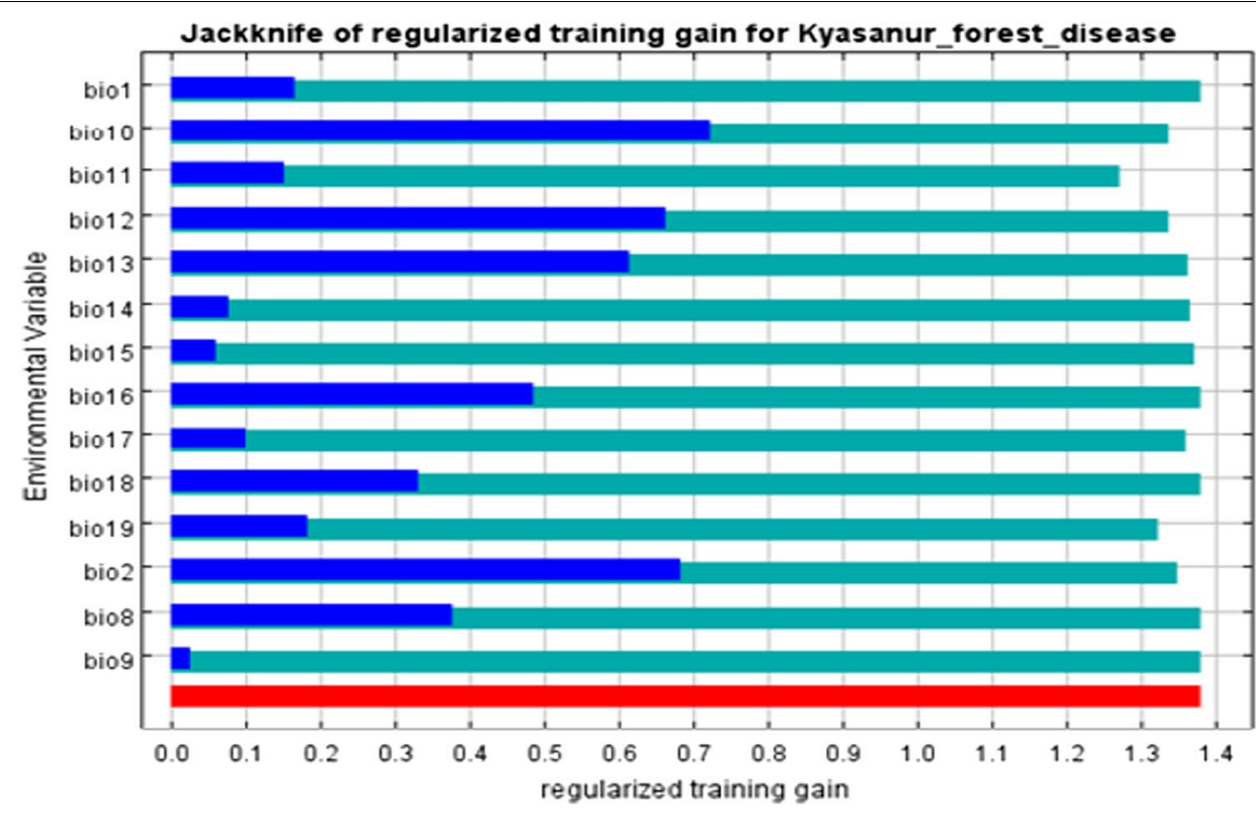

Without variable $=$ With only variable = With all variables $=$

Fig. 4 The Jackknife test results indicating the relative importance of bio-climatic variables

area mapping of KFD. Both variables generate the best prediction results when used individually from Jackknife analysis. Figure 4 shows the Jackknife test results of the climatic variable importance as estimated by the model.

\section{Association of Haemaphysalis spinigera tick to climatic variables}

Figure $5 a-n$ indicates individual response curves of the association between each bio-climatic variable and the possibility of Haemaphysalis spinigera tick presence as estimated by the model. The response curves from the model's performance show the differences in the logistic value conveyed by alteration in each parameter if the mean value of all other variables is preserved. However, there is an overall non-linear negative relationship detected for the annual average temperature (bio1), the average temperature of the warmest quarter (bio10), the average temperature of the driest quarter (bio9), and mean temperature of the wettest quarter (bio8) indicating that higher the temperature intensity, the lower would be the Haemaphysalis spinigera tick distribution. Haemaphysalis spinigera tick preferred habitat having an annual mean temperature (bio1) between 23 and $26.2{ }^{\circ} \mathrm{C}$, mean temperature of the driest quarter (bio9) between 20 and $28{ }^{\circ} \mathrm{C}$, and mean temperature of the wettest quarter (bio8) between 22.5 and $25^{\circ} \mathrm{C}$. Precipitation of the wettest period and annual precipitation showed a non-linear positive response, indicating that the higher the precipitation intensity, the higher the Haemaphysalis spinigera tick distribution. The mean temperature of the warmest quarter (bio10) represented the temperature in the warmest season and revealed a significant probability of Haemaphysalis spinigera presence between 25.4 and $30{ }^{\circ} \mathrm{C}$. The mean diurnal temperature range is the difference between daily maximum and daily minimum temperature, and it revealed a very high probability of tick presence between 8 and $10{ }^{\circ} \mathrm{C}$. The response to precipitation of the wettest period (bio13) showed that precipitation of 500-650 mm highly favoured the presence of Haemaphysalis spinigera tick. The other optimum bioclimatic parameters for Haemaphysalis spinigera tick suitability are shown in Table 1 . Subsequently, the high tick population could be a cause for monkey death and the human case.

\section{Potential risk areas of Haemaphysalis spinigera}

We converted the predicted probability map of Haemaphysalis spinigera tick suitability from the MaxEnt model to presence and absence using the 'max SSS' logistic threshold value. The predicted presence areas were classified as very high to moderately suitable areas, and the absence areas were classified as non-suitable areas for Haemaphysalis spinigera. Based on the proportion of bioclimatic suitability areas, the potential suitability map was classified into five different suitability categories, i.e., 'very high suitability' $(0.80-$ $1.0)$, 'high suitability' $(0.79-0.60)$, 'moderate suitability' (0.59-0.40), 'low suitability' (0.39-0.20), and 'very low suitable' class $(0-0.19)$. The predicted potential 


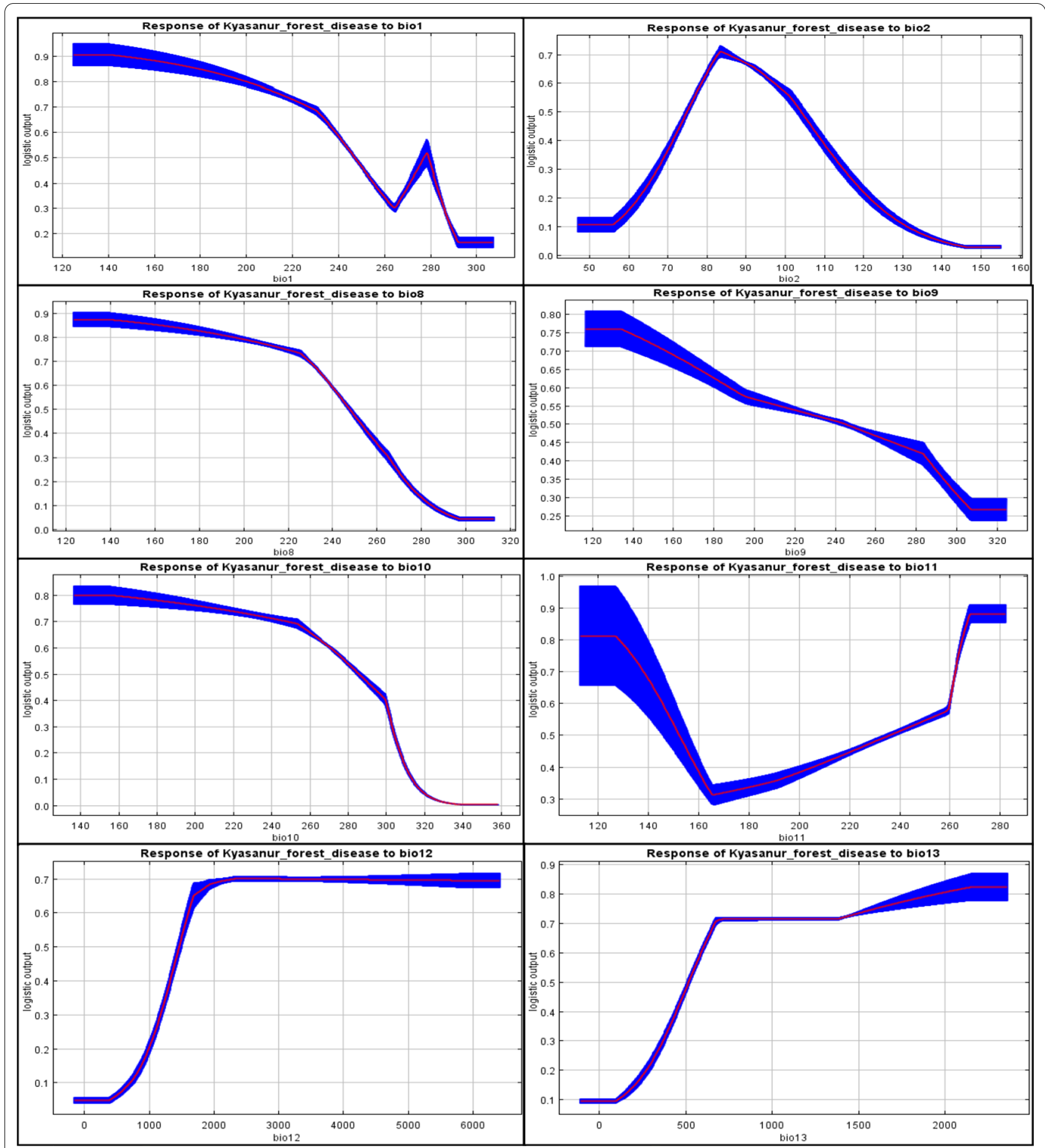

Fig. 5 Relationship between selected climatic variables and probability of the presence of Haemaphysalis spinigera ticks. a Annual mean temperature $\left(\mathrm{bio} 1,{ }^{\circ} \mathrm{C}\right), \mathbf{b}$ mean diurnal temperature range $\left(\mathrm{bio} 2,{ }^{\circ} \mathrm{C}\right), \mathbf{c}$ mean temperature of wettest quarter (bio8, $\left.{ }^{\circ} \mathrm{C}\right), \mathbf{d}$ mean temperature of driest quarter (bio9, mm), e mean temperature of warmest quarter (bio10, mm), $\mathbf{f}$ mean temperature of coldest quarter (bio 11, CV), $\mathbf{g}$ annual precipitation (bio 12, mm), $\mathbf{h}$ precipitation of wettest period (bio 13, $\mathrm{mm}$ ), i precipitation of driest month (bio $14, \mathrm{~mm})$, j precipitation seasonality (bio15, CV), $\mathbf{k}$ precipitation of wettest quarter (bio 16, mm), I precipitation of driest quarter (bio17, mm), $\mathbf{m}$ precipitation of warmest quarter (bio18, $\mathrm{mm}), \mathbf{n}$ precipitation of coldest quarter (bio 19, $\mathrm{mm}$ ). Red curves indicate the average response and blue margins signify \pm SD estimated over 50 replicates 


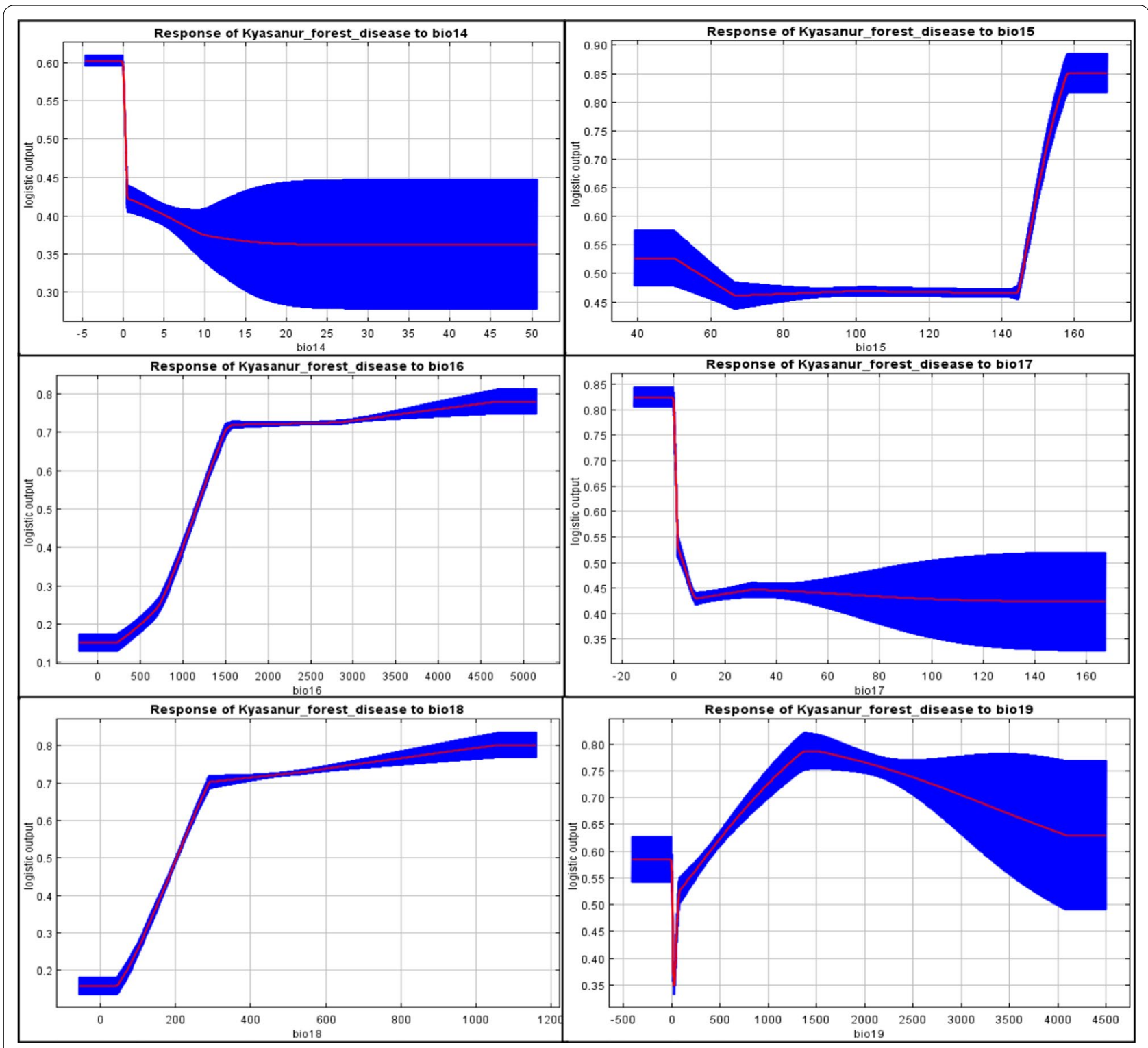

Fig. 5 continued

areas of Haemaphysalis spinigera under present bioclimatic settings are shown in Fig. 6. As per results, about $26,429 \mathrm{~km}^{2}(4 \%)$ area comes under 'very high potential' for Haemaphysalis spinigera, followed by 'high potential' at 18,258 (3\%) and 'moderate potential' at $45,759 \mathrm{~km}^{2}(7 \%)$ (Table 2). The results further show that Karnataka is the most potential region, followed by Maharashtra, Kerala, Goa, and Tamil Nadu. The high to very high suitable areas are Shivamogga, Chamrajnagar, Chikmagalur in Karnataka; Kozhikode and Wayanad districts in Kerala; Raigad, Ratnagiri districts in Maharashtra; Nilgiris district in Tamil Nadu; North Goa district in Goa, requiring continuous vigilance (Fig. 6).
The district-wise suitability map shows linear spatial clustering along the western Ghats as a very high-risk zone of the potential distribution of Haemaphysalis spinigera. In those districts, extensive survey, continuous vigilance is required, especially from November to March, when most KFD cases occur. The percentage of the risk area in each state is shown in Table 3.

\section{Discussion}

This is the first study to link the bioclimatic variables with the potential distribution of Haemaphysalis spinigera tick in South India. Based on tick occurrence records, MaxEnt modelled the potential distribution of Haemaphysalis 


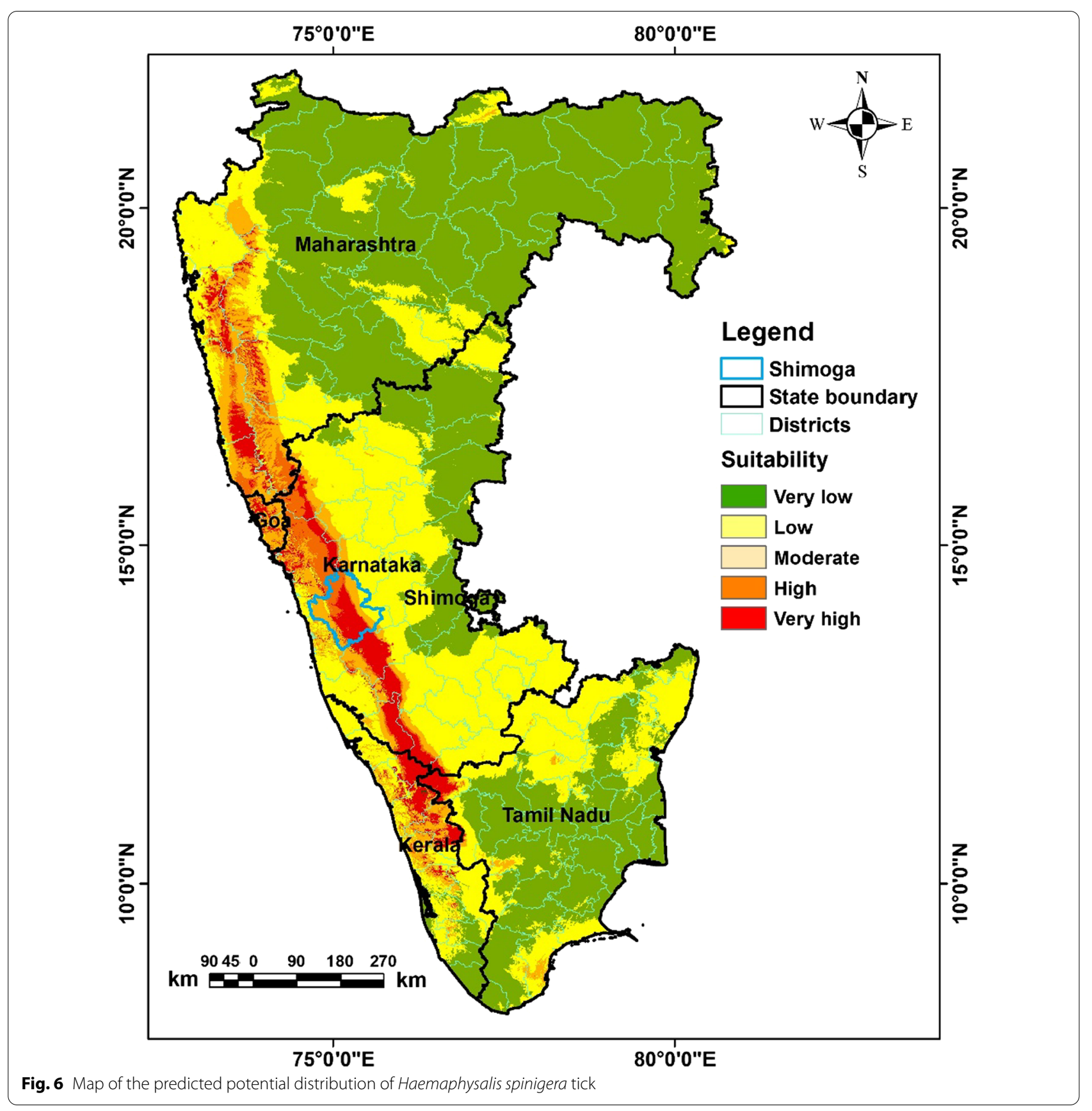

Table 2 Area under different risk classes for KFD tick

\begin{tabular}{lcc}
\hline Risk categories & Area (sq. $\mathbf{k m})$ & Area in \% \\
\hline Very low risk & 359,767 & 53 \\
Low risk & 220,650 & 33 \\
Medium risk & 45,769 & 7 \\
High risk & 18,258 & 3 \\
Very high risk & 26,429 & 4 \\
Total & 670,873 & 100 \\
\hline
\end{tabular}

spinigera tick as 23,265 sq. km (58.66\%) spread over the Shivamogga, Chamrajnagar, and Chikmagalur districts in Karnataka; 4765 sq. km (12.02\%) in Kozhikode and Wayanad districts of Kerala; 7198 sq. km (18.15\%) in Raigad, Ratnagiri districts of Maharashtra; the Nilgiris districts in Tamil Nadu; North Goa district in Goa (Fig. 6). The region is characterized by the mix of wet and dry climatic conditions, but most of the KFD affected regions are located in the eastern regions of the Western Ghats. These locations lie in the rain shadow region, receive far 
Table 3 State-wise high risk area for KFD tick

\begin{tabular}{lclc}
\hline States & High suitable area $\left.\mathbf{( k m}^{2}\right)$ & $\begin{array}{l}\% \text { of very highly suitable area in the total } \\
\text { suitability }\end{array}$ & $\begin{array}{l}\text { \% of very highly } \\
\text { suitable area in the } \\
\text { state }\end{array}$ \\
\hline Goa & 2056 & 5.18 & 55.66 \\
Karnataka & 23,265 & 58.66 & 12.16 \\
Kerala & 4765 & 12.02 & 12.64 \\
Maharashtra & 7198 & 18.15 & 2.34 \\
Tamil Nadu & 2376 & 5.99 & 1.82 \\
Total area & 39,660 & 100 & \\
\hline
\end{tabular}

less rainfall and long dry spells [36]. Therefore, most of the districts in Karnataka as well as southern India are suitable for KFD in present climatic conditions as they are located in the rain shadow [36].

The relationship between the growing distribution of Haemaphysalis spinigera tick and variations in the mean temperature of warmest quarter (bio10) and mean diurnal temperature range (bio2) means dry and warmer climatic conditions were evident in the model results [16-18]. The risk areas of Haemaphysalis spinigera tick were more intense in the locations with precipitation of wettest period 500-650 mm, mean diurnal temperature range $8-10{ }^{\circ} \mathrm{C}$ and mean temperature of the warmest quarter $25.4-30{ }^{\circ} \mathrm{C}$, which is relatively hot and dry over the study region. KFD's transmission occurs during the non-rainy season as the nymphs of Haemaphysalis spinigera ticks are active during this season (Fig. 2).

Human encroachment and deforestation in the affected area increases the encounters with infected Haemaphysalis spinigera ticks. Furthermore, deforestation affects the local precipitation pattern, thus impacting the micro-climate of the region. The results shows that the predicted risk areas are expanding in hot and drier climatic conditions, as the tick's distribution and lifecycle heavily depend on the precipitation and temperature of this region [15]. Human activity peaks post monsoon for the paddy harvest, gathering firewood, forest products and the collection of other livelihoods $[8,15]$. The expansion in areas of the tick population in Africa was related to variations in temperature and precipitation [56]. Moreover, a warmer temperature has been found as the most influential factor for the geographic range shifting of some tick species $[57,58]$. According to the previous studies, climatic variables have contributed to the expanded range of ticks, potentially increasing the risk of Lyme disease e.g. in areas of Canada where ticks were previously unable to survive [59]. Temperature has a significant impact on the life cycle and prevalence of deer ticks [60].
In the states of Karnataka, Goa, Maharashtra, Kerala, Tamil Nadu, the increasing distribution of Haemaphysalis spinigera tick mainly was seen in the deciduous and neighbouring semi-evergreen and evergreen areas [61] (Fig. 1). Studies showed that these forested lands were more prone to dry climate with decreasing precipitation [62]. The decrease in precipitation during the pre-monsoon (southwest) resulted in short-term meteorological droughts in this region [63, 64], which increases the suitable areas of Haemaphysalis spinigera tick. Secondly in the areas with reported KFD cases, annual rainfall was relatively lower, and temperature somewhat higher than KFD cases free areas. Human get infected through the bite of nymphal ticks, which are mostly active during the hot and dry season in the study region [62]. According to Raj and Azeez [65], and Nair et al. [66] the aridity index increases significantly in the region, therefore the risk areas of Haemaphysalis spinigera tick may influence the significant rise in KFD cases in the region. The results of the present study indicates that the potential tick suitability increases, when the mean temperature of the warmest quarter ranges between 25.4 and $30{ }^{\circ} \mathrm{C}$, and more than $30{ }^{\circ} \mathrm{C}$ is not suitable. Even ticks die because of water loss due to destruction in the integument. Moreover, the endemic areas of KFD in the Shivamogga district are also shifting from Shivamogga to Thirthahalli, Hosangara taluka, which are presently the most endemic region in Shivamogga district (Fig. 7). According to bio-climatic data, a suitable diurnal temperature range and mean warmest month temperature with low precipitation was found in the high endemic talukas, as mentioned earlier than the low endemic areas of Shivamogga taluka which can explain the reason for the high endemicity of KFD (Fig. 2).

Accordingly, our results also indicate a significant increase in distribution of Haemaphysalis spinigera or risk areas of KFD with favourable climatic conditions (warmest month temperature and diurnal temperature range) in seven regions, namely Shivamogga, Chamarajanagar, Bandipur National Park, Madurai Tiger Reserve, 


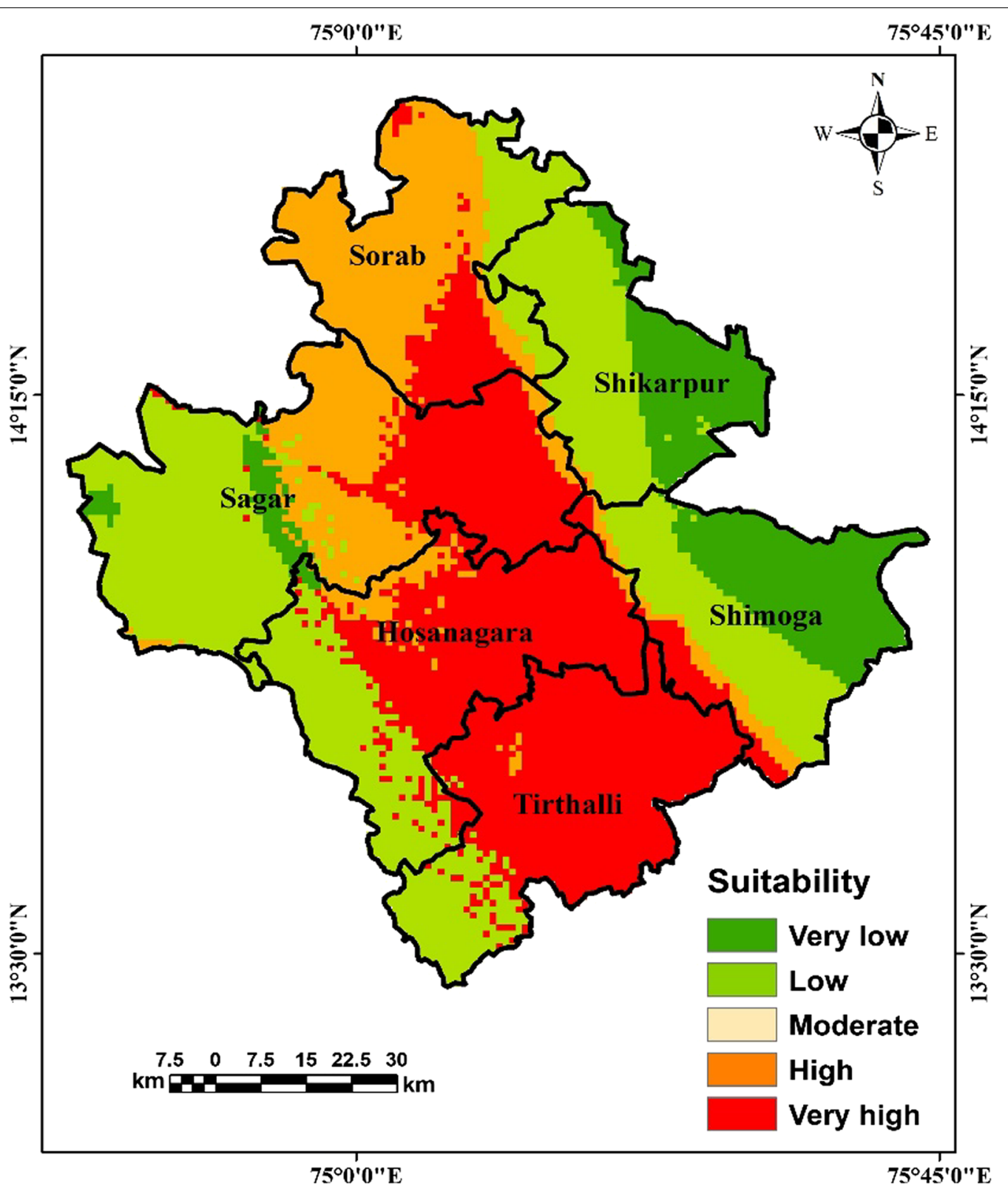

Fig. 7 Predicted potential distribution of Haemaphysalis spinigera tick in endemic region of Shivamogga district

Wayanad, Sattari, Malappuram, where the highest number of monkey death and human cases were observed.

Moreover socio-economic factors may also be having an influence on KFD transmission in Shivamogga, which need further study. Other factors like, migration of ticks and reservoir hosts, increased human contact with infected animals, migratory birds and bats including the climate change may play an important role to understand the threat of KFD cases.

Species distribution modelling is known as 'habitat suitability, 'ecological niche', and 'potential distribution' modelling and these are used to predict the suitable habitats [67] of a tick species. In this study, we limited the increasing distribution of Haemaphysalis spinigera tick potentiality in terms of climatic variables and tick occurrences' to identify the climatic determinants in the habitat alteration in southern India. The role of deforestation has been found in hot spots of KFD in western Ghats [68] which may further be elucidated using satellite remote sensing.

We omitted land use and land cover variables because the ticks' distribution is associated with deciduous, 
evergreen, and semi-evergreen forest [61]. The role of low mammalian richness has also been found in outbreaks of KFD [69].

Soil characteristics were also excluded from this study since the high resolution and more accurate data were not available. Moreover, we also excluded the role of host-agent-environment factors due to the lack of proper information over this region. Regardless, further spread of Haemaphysalis spinigera tick may be affected by climate change, emphasizing the need for further studies.

It has been observed that the improvement in diagnostic assay through Virus Research Diagnostic Lab established in Shivamogga and tick monitoring are affecting disease awareness and better reporting.

Our study used Maxent bio-climatic model and studying the ecology was not the main aim. However, detailed ecological studies using remote sensing, forestry, anthropology and veterinary domains for threat of KFD are warranted. Understanding the ecology and epidemiology of a tick-borne disease is indeed multifactorial which cannot be answered by one study. That is why One Health approach is being adopted to address such zoonotic diseases comprehensively.

\section{Conclusion}

The bio-climate envelop modelling approach has been found as a useful tool to link bio-climatic variables with the present and predicted distribution of Kyasanur forest disease. It has predicted the potential climatic suitability of KFD in Shivamogga, Chamrajnagar, Chikmagalur in Karnataka; Kozhikode and Wayanad districts in Kerala; Raigad, Ratnagiri districts in Maharashtra; the Nilgiris district in Tamil Nadu; North Goa district in Goa. These districts are categorized as dry and hot climates than other districts of the study area. The predicted potential risk map emphasized the significance of climatic variables in identifying the potential risk district for KFD warranting surveillance for KFD in hitherto KFD-free contiguous areas. Better understanding of KFD emergence linking with climatic factors with ecology using satellite remote sensing, deforestation and mammalian population density will help to build accurate surveillance system allowing to track spread and emerging pathways. Future studies should be designed incorporating further risk variables (i.e. monkey dispersal pattern, seasonal forest characteristics, climate change, socioeconomic factors host-agent-environment factors (One Health approach) in Shivamogga district, western Ghats and the southern states of India.

\section{Supplementary Information}

The online version contains supplementary material available at https://doi. org/10.1186/s12879-021-06908-9.

Additional file 1: Table S1. Showing reported tick presence (Haemaphysalis spinigera), monkey death and human cases in Karnataka, Tamil Nadu, Goa, Maharashtra state of India. Table S2. Climatic variables selected for the preliminary and final model. Table S3. Correlation matrix among the bio-climatic variables. The Cut-off threshold values are shown $(r \geq 0.8)$ in bold.

\section{Acknowledgements}

The authors would like to acknowledge the Department of Science and Technology (New Delhi, India), Climate Change Programme (SPLICE), Govt. of India for funding this project (No. DST/CCP/CoE/82/2017(G)). Thanks are also due to State Programme Officer, Karnataka and to staff of VRDL, Shivamogga for logistic support in the fieldwork. The authors express their gratitude to field staff Shri Surender Kumar and Shri Chandra Prakash Arya for support in the ground-truth survey.

\section{Authors' contributions}

MP-data collection, data processing, model development, and drafting of the manuscript. PS-data collection and drafting of the manuscript, RCD-conception, analysis, drafting and critical revision of the manuscript. All authors read and approved the final manuscript.

\section{Funding}

This research was funded by Department of Science \& technology, Govt. of India, under Grant number DST/CCP/CoE/82/2017(G).

\section{Availability of data and materials}

The datasets of bioclimatic variables analysed during the current study is available in the WorldClim Version2 (http://www.worldclim.com/version2). Further, the datasets generated used and analysed during the current study are available from the corresponding author on reasonable request. All data generated or analysed during this study are included in this published article and further details are available in additional information files.

\section{Declarations}

Ethics approval and consent to participate Not applicable.

Consent for publication

Not applicable.

\section{Competing interests}

The authors declare that they have no competing interests.

Received: 3 January 2020 Accepted: 25 November 2021 Published online: 07 December 2021

\section{References}

1. Work TH. Virological epidemiology of the 1958 epidemic of Kyasanur forest disease. Am J Public Health Nations Health. 1959:49(7):869-74.

2. Singh KR, Pavri K, Anderson CR. Experimental transovarial transmission of Kyasanur forest disease virus in Haemaphysalis spinigera. Nature. 1963;199:513.

3. Boshell MJ. Isolation of Kyasnur forest disease virus from Ixodid ticks: 1961-1964. Indian J Med Res. 1968;56(4):541-68.

4. Yadav PD, Patil DY, Sandhya VK, Prakash KS, Surgihalli R, Mourya DT. Outbreak of Kyasanur Forest disease in Thirthahalli, Karnataka, India. Int J Infect Dis. 2014;26:132-4.

5. Banerjee K, Bhatt HR. Kyasanur forest disease. In: Mishra A, Polasa H, editors. Virus ecology. New Delhi: South Asian Publisher; 1984. p. 123-38. 
6. Banerjee K. Kyasanur Forest disease. In: Monath TP, editor. Arboviruses: epidemiology and ecology. Boca Raton (FL): CRC Press; 1990. p. 93-116.

7. Bhatt PN, Work TH, Varma MG, Trapido H, Murthy DP, Rodrigues FM. Kyasanur forest diseases. IV. Isolation of Kyasanur forest disease virus from infected humans and monkeys of Shivamogga district Mysore state. Indian J Med Sci. 1966;20:316-20.

8. Pattnaik P. Kyasanur forest disease: an epidemiological view in India. Rev Med Virol. 2006;16:151-65.

9. Trapido H. Kyasanur Forest disease. VIII. Isolation of Kyasanur Forest disease virus from naturally infected ticks of the genus Haemaphysalis. Indian J Med Res. 1959:47:133-8.

10. Verma MG, Webb HE, Pavri KM. Studies on the transmission of Kyasanur Forest disease virus by Haemaphysalis spinigera Newman. Transfusion (Paris). 1960;54:509-16.

11. Singh KRP, Pavri K. Survival of Kyasanur forest disease virus in infected ticks, Haemaphysalis spinigera, after feeding on immune rabbits. Indian J Med Res. 1965;53(9):827-30.

12. Sreenivasan MA, Bhat HR, Rajagopalan PK. The epizootics of Kyasanur Forest disease in wild monkeys during 1964 to 1973. Trans R Soc Trop Med Hyg. 1986;80:810-4.

13. Work TH, Roderiguez FM, Bhatt PN. Virological epidemiology of the 1958 epidemic of Kyasanur Forest disease. Am J Public Health Nations Health. 1959;49:869-74.

14. Ajesh K, Nagaraja BK, Sreejith K. Kyasanur forest disease virus breaking the endemic barrier: an investigation into ecological effects on disease emergence and future-outlook. Zoonoses Public Health. 2017;64(7):73-80.

15. Nichter M. Kyasanur forest disease: an ethnography of a disease of development. Med Anthropol Q. 1987;1(4):406-23.

16. John JK, Kattoor JJ, Nair AR, Bharathan AP, Valsala R, Sadanandan GV. Kyasanur forest disease: a status update. Adv Anim Vet Sci. 2014;2:329-36

17. Rajagopalan PK, Patil AP, Boshell J. Studies on the ixodid tick populations on the forest floor in the Kyasanur forest disease area. Indian J Med Res. 1968:56:497-509.

18. Rajagopalan PK, Patil AP, Boshell J. Ixodid ticks on their mammalian hosts in the Kyasanur forest disease area of Mysore State, India. Indian J Med Res. 1968;56(510):525.

19. Work TH, Trapido H. Summary of preliminary report of investigations of the virus research centre on an epidemic disease affecting forest villagers and wild monkeys in Shimoga district, Mysore. Indian J Med Sci. 1957:11:340-1.

20. Kasabi GS, Murhekar MV, Yadav PD, Raghunandan R, Kiran SK, Sandhya VK, Mehendale SM. Kyasanur Forest disease, India, 2011-2012. Emerg Infect Dis. 2013;19:278-81.

21. Mourya DT, Yadav PD, Patil DY. Highly infectious tick-borne viral diseases: Kyasanur forest disease and crimean-congo haemorrhagic fever in India. WHO South-East Asia J Public Health. 2014;3:8-21.

22. Mourya DT, Yadav PD, Sandhya VK, Reddy S. Spread of Kyasanur forest disease, Bandipur tiger reserve, India, 2012-2013. Emerg Infect Dis. 2013;19:1540-1.

23. Tandale BV, Balakrishnan A, Yadav PD, Marja N, Mourya DT. New focus of Kyasanur forest disease virus activity in a tribal area in Kerala, India. Infect Dis Poverty. 2015:4:12

24. Phillips SJ, Dudik $M$, and Schapire RE. A maximum entropy approach to species distribution modelling. In: Proceedings of the 21 st international conference on machine learning. 2004

25. Yang XQ, Kushwaha SPS, Saran S, Xu J, Roy PS. MaxEnt modelling for predicting the potential distribution of medicinal plant Justicia adhatoda L. in Lesser Himalayan foothills. Ecol Eng. 2013;51:83-7.

26. Arnould JPY, Monk J, lerodiaconou D, Hindell MA, Semmens J, Hoskins AJ, et al. Use of anthropogenic seafloor structures by Australian fur seals: potential positive ecological impacts of marine industrial development? PLOS ONE. 2015:10:e0130581.

27. Manyangadze T, Chimbari MJ, Gebreslasie M, Ceccato P, Mukaratirwa S. Modelling the spatial and seasonal distribution of suitable habitats of schistosomiasis intermediate host snails using Maxent in Ndumo area, KwaZulu-Natal Province, South Africa. Parasit Vectors. 2016:9:572.

28. Gao X, Wang H, Wang H, Qin H, Xiao J. Land use and soil contamination with Toxoplasma gondii oocysts in urban areas. Sci Total Environ. 2016;568:1086-91.
29. Chikerema SM, Murwira A, Matope G, Pfukenyi DM. Spatial modelling of Bacillus anthracis ecological niche in Zimbabwe. Prev Vet Med. 2013:111:25-30.

30. Wang L, Hu W, Soares Magalhaes RJ, Bi P, Ding F, Sun H, et al. The role of environmental factors in the spatial distribution of Japanese encephalitis in mainland China. Environ Int. 2014;73:1-9.

31. Ren Z, Wang D, Ma A, et al. Predicting malaria vector distribution under climate changes scenarios China: challenges for malaria elimination. Sci Rep. 2016;6:20604.

32. Gao X, Xiao JH, Liu BY, Wang HB. Impact of meteorological and geographical factors on the distribution of Phlebotomus chinensis in northwestern mainland China. Med Vet Entomol. 2018;32:365-71.

33. Liu B, Gao X, Ma J, Jiao Z, Xiao J, Hayat MA, Wang H. Modelling the present and future distribution of arbovirus vectors Aedes aegypti and Aedes albopictus under climate change scenarios in Mainland China. Sci Total Environ. 2019;664:203-14.

34. Conley AK, Fuller DO, Haddad N, Hassan AN, Gad AM, Beier JC. Modelling the distribution of the West Nile and Rift Valley fever vector Culex pipiens in arid and semi-arid regions of the Middle East and North Africa. Parasit Vectors. 2014;7:289.

35. Miller RH, Masuoka P, Klein TA, Kim HC, Somer T, Grieco J. Ecological niche modeling to estimate the distribution of Japanese encephalitis virus in Asia. PLoS Negl Trop Dis. 2012;6:119-21.

36. Pramanik M, Paudel U, Mondal B, Chakraborti S, Deb P. Predicting climate change impacts on the distribution of the threatened Garcinia Indica in the Western Ghats, India. Clim Risk Manage. 2018;19:94-15.

37. Sallam MF, Xue RD, Pereira RM, Koehler PG. Ecological niche modeling of mosquito vectors of West Nile virus in St. John's County, Florida, USA. Parasit Vectors. 2016;9:371.

38. Messina JP, Moore NJ, DeVisser MH, McCord PF, Walker ED. Climate change and risk projection: dynamic spatial models of Tsetse and African Trypanosomiasis in Kenya. Ann Assoc Am Geogr. 2012;102(5):1038-48.

39. Thompson I, Mackey B, McNulty S, Mosseler A. A Synthesis of the biodiversity/resilience/stability relationship in forest ecosystems. Forest resilience, biodiversity, and climate change. Secretariat of the Convention on Biological Diversity, Montreal. Technical series 2009:43:67.

40. Hijmans RJ, Graham CH. A comparison of methods for mapping species ranges and species richness. Glob Ecol Biogeogr. 2006;15:578-87.

41. Loiseau C, Harrigan RJ, Bichet C, et al. Predictions of avian Plasmodium expansion under climate change. Sci Rep. 2013;3:1126.

42. Remya K, Ramachandran A, Jayakumar S. Predicting the current and future suitable habitat distribution of Myristica dactyloides Gaertn, using MaxEnt model in the Eastern Ghats, India. Ecol Eng. 2015;82:184-8.

43. Peterson AT, Papes M, Eaton M. Transferability and model evaluation in ecological niche modelling: a comparison of GARP and Maxent. Ecography. 2007;30:550-60.

44. Elith J, Phillips SJ, Hastie T, Dudik M, Chee YE, Yates CJ. A statistical explanation of Maxent for ecologists. Divers Distrib. 2011;17:43-57.

45. Jaynes ET. Information theory and statistical mechanics. Phys Rev. 1957;106:620-30

46. Anderson RP, Raza A. The effect of the extent of the study region on GIS models of species geographic distributions and estimates of niche evolution, preliminary tests with montane rodents (genus Nephelomys) in Venezuela. J Biogeogr. 2010;37:1378-93.

47. Rospleszcz S, Janitza S, Boulesteix AL. The effects of bootstrapping on model selection for multiple regression. Technical Report 164. 2014, Department of Statistics, University of Munich.

48. Phillips SJ, Dudík M. Modelling of species distributions with Maxent: new extensions and a comprehensive evaluation. Ecography. 2008;31:161-75.

49. Allouche O, Tsoar A, Kadmon R. Assessing the accuracy of species distribution models: prevalence, kappa and the true skill statistic (TSS). J Appl Ecol. 2006:43(6):1223-32.

50. Liu C, White M, Newell G. Selecting thresholds for the prediction of species occurrence with presence-only data. J Biogeogr. 2013:40(4):778-89.

51. Bosso L, Smeraldo S, Rapuzzi P, Sama G, Garonna AP, Russo D. Nature protection areas of Europe are insufficient to preserve the threatened beetle Rosalia alpine (Coleoptera: Cerambycidae): evidence from species distribution models and conservation gap analysis. Ecol Entomol. 2018:43(2):192-203.

52. Smeraldo S, Di Febbraro M, Ciroviic D, Bosso L, Trbojeviic I, Russo D. Species distribution models as a tool to predict range expansion after 
reintroduction: a case study on Eurasian beavers (Castor fibre). J Nat Conserv. 2017:37:12-20.

53. Brown JL, Bennett JR, French CM. SDMtoolbox2.0: the next generation Python-based GIS toolkit for landscape genetic, biogeographic and species distribution model analyses. Peer J. 2017;5:e4095.

54. Fielding AH, Bell JF. A review of methods for the assessment of prediction errors in conservation presence/absence models. Environ Conserv. 1997;24:38-49.

55. Thuiller W, Richardson DM, Pysek P, Midgley GF, Hughes GO, Rouget M. Niche-based modelling as a tool for predicting the global risk of alien plant invasions at a global scale. Glob Change Biol. 2005;11:2234-50.

56. Cumming GS. Comparing climate and vegetation as limiting factors for species ranges of African ticks. Ecology. 2002;83:255-68.

57. Danielova V, Rudenko N, Daniel M, Holubova J, Materna J, Golovchenko $M$, Schwarzova L. Extension of Ixodes ricinus ticks and agents of tickborne diseases to mountain areas in the Czech Republic. Int J Med Microbiol. 2006;296(Suppl. 40):48-53.

58. Lindgren E, Talleklint L, Polfeldt T. Impact of climatic change on the northern latitude limit and population density of the disease-transmitting European tick/xodes ricinus. Environ Health Perspect. 2000:108:119-23.

59. Beard CB, Eisen RJ, Barker CM, Garofalo JF, et al. Chapter 5: Vector-borne diseases. In: The impacts of climate change on human health in the United States: a scientific assessment. U.S. Global Change Research Program. 2012.

60. Leighton PA, Koffi JK, Pelcat Y, Lindsay LR, Ogden NH. Predicting the speed of tick invasion: an empirical model of range expansion for the Lyme disease vector Ixodes scapularis in Canada. J Appl Ecol. 2012;49(2):457-64.

61. Mehla R, Kumar SR, Yadav P, Barde PV, Yergolkar PN, Erickson BR. Recent ancestry of Kyasanur Forest disease virus. Emerg Infect Dis. 2009:15:1431-7.

62. Prasad VK, Badarinath KVS, Eaturu A. Effect of precipitation, temperature, and topographic parameters on evergreen vegetation greenery in the Western Ghats, India. Int J Climatol. 2008;28:1807-19.

63. Krishna Kumar KN, Rao GP, Gopakumar CS. Rainfall trends in the twentieth century over Kerala, India. Atmos Environ. 2009;43(11):1940-4.

64. Subash N, Sikka AK. Trend analysis of rainfall and temperature and its relationship over India. Theoret Appl Climatol. 2014;117(3-4):449-62.

65. Raj PPN, Azeez PA. Changing rainfall in the Palakkad plains of South India. Atmosfera. 2010;23:75-82

66. Nair VS, Babu SS, Moorthy KK, Prijith SS. Spatial gradients in aerosolinduced atmospheric heating and surface dimming over the oceanic regions around India: anthropogenic or natural? I Clim. 2013;26(19):7611-21.

67. Elith J, Graham CH. Do they? How do they? WHY do they differ? On finding reasons for differing performances of species distribution models. Ecography. 2009;1:66-77.

68. Walsh MG, Mor SM, Maity H, Hossain S. Forest loss shapes the landscape suitability of Kyasanur Forest disease in the biodiversity hotspots of the Western Ghats, India. Int J Epidemiol. 2019;48(6):1804-14. https://doi.org/ 10.1093/ije/dyz232.

69. Walsh MG, Bhat R, Nagarajan-Radha V, Narayanan P, Vyas N, Sawleshwarkar S, Mukhopadhyay C. Low mammalian species richness is associated with Kyasanur Forest disease outbreak risk in deforested landscapes in the Western Ghats. India One Health. 2021;13:100299.

\section{Publisher's Note}

Springer Nature remains neutral with regard to jurisdictional claims in published maps and institutional affiliations. 